\title{
An Economic Analysis of Heritage as Commons: Reflections on Theory, Methodology and Social Imagery
}

\author{
Mina Dragouni
}

The term 'commons' is used to describe a particular type of institutional arrangement for governing the availability and use of a good. As Hardt and Negri (2009) observe, we tend to see the world as divided between the public/ state and private/market spheres. This perceptual dichotomy creates implications not only in conceptualising heritage commons but also in addressing issues related to their political economy. To deal with these complexities, this chapter embraces economics and seeks to position heritage commons within the relevant theoretical and methodological approaches - in particular, the branch of behavioural experimental economics that provides tools for exploring the mechanics of collective decision-making and individuals' responses to social dilemmas. Moreover, the chapter engages in a discussion on macroeconomic issues and the interplay between a potential (local) self-governing arrangement and the external economic and political influences that threaten to undermine its effectiveness to resolve commons problems.

According to economic theory, the concept of the common or Common Pool Resource is imbued with the attributes of non-excludability and rivalry (Ostrom et al., 1994). Indeed, there is a plethora of heritage resources that

How to cite this book chapter:

Dragouni, M. 2020. An Economic Analysis of Heritage as Commons: Reflections on Theory, Methodology and Social Imagery. In Lekakis, S. (ed.) Cultural Heritage in the Realm of the Commons: Conversations on the Case of Greece. Pp. 45-66. London: Ubiquity Press. DOI: https://doi.org/10.5334/bcj.d. License: CC-BY 
bear these traits and are in principle (and often in practice) communal goods, implying that it is particularly difficult to exclude their potential beneficiaries from enjoying them. While the imposition of certain restrictions can set some limits on our encounters with heritage physically, it remains impossible to defend, both legally and economically, the enclosure of intangible values that we derive from the remains and practices of the past. Parallel to this, heritage goods can be viewed as rival in the sense that the (over)extraction of value by certain users can reduce availability for others. This is manifested, for example, in places where there is limited capacity and excessive development, or in cases where the uses of heritage antagonise disparate value systems.

Investment in common and non-market heritage goods is supposed to generate positive externalities that benefit society as a whole (Frischemann 2005). However, it is argued here that current regimes, such as centralized management, often fail to serve the communal interests of heritage sufficiently, whereas recently emerging market-led policies further jeopardise the communal character of heritage goods. As will be discussed, when the state follows management practices (e.g. selection, interpretation, public representation) that are expert-driven and exclusionary, it essentially de-socialises heritage resources and causes the alienation of non-expert communities. At the same time, when central administration adopts neoliberal strategies that prescribe funds for allocation that disproportionately favour private interests (e.g. the real estate and tourism sectors), it again fails to summon up the heritage communal principle. Given these shortcomings, the commons, which increasingly generate debate over public access to environmental and cultural resources, are viewed as an alternative to government control and an antidote to privatisation (Frischemann, 2005; Hardt \& Negri 2009).

Admittedly, a central complexity imbued within the commons relates to provision arrangements and the behavioural responses of appropriators when it comes to contributing resources for maintaining them (Ostrom et al. 1994). In principle, commons are managed and sustained by communities themselves, through social networks that rely on solidarity and exchange (De Angelis 2003). Based on economic thinking, complexity stems from the fact that provision to and appropriation of heritage goods are disconnected, meaning that the former is not a precondition for the latter due to non-excludability. This leads to dilemmas between individual and collective interests, as personal gains compete with the provision of an optimal mix of communal benefits. To address these complications, this chapter analyses some key ideas of mainstream economics related to the subject, drawing mainly on the seminal work of Elinor Ostrom. Ostrom (1990) challenged the prevailing notions surrounding common goods, primarily those conceptualised in Olson's Logic of Collective Action (1965) and Hardin's Tragedy of the Commons (1968). The prediction of these theories was that in situations where resources are jointly shared, potential collective benefits will not be achieved due to excessive appropriation and the 
temptation to free ride. Contrary to these gloomy prognoses, in her book, Governing the Commons (1990), Ostrom compiled a series of micro-level cases in which users had in fact avoided tragic outcomes. Rather, these small communities had managed to sustain their commons by establishing their own rules, or in the author's terms, 'institutional arrangements' to regulate contribution and appropriation.

Economic studies on Common Pool Resources have been systematic in exploring mainly natural resources, focusing on individuals and the circumstances that drive their decisions. However, as is shown here, the commonpool metaphor is particularly relevant to heritage, the collective management of which entails control assignment to local actors and a horizontal collaboration between experts and citizens. In some respects, the heritage commons call for a socio-political arrangement located at Arnstein's (1969) highest rungs of 'citizen participation' ladder. Although there is high interest in the concept of managing heritage goods such as commons, there is considerably less evidence on how to do so in an effective and viable way. For those engaging in scientific research on the subject, the idea of commons inevitably leads to some serious methodological considerations. As it is outlined, there is a serious limitation to the empirical study of heritage commons due to the scarcity of naturally occurring data that are vital for gaining a better understanding of how models of heritage self-governance can work in practice.

Considering these limitations and bearing in mind that understanding human behaviour towards the commons is itself a great challenge (Ostrom et al. 1994), this chapter proposes the use of economic experiments as complementary methodological tools to address the implications of empirically investigating heritage commons and increase our current knowledge of the communal drivers and arrangements that can make collective management a viable alternative. As will be shown, there are two features of economic experiments that render this possible. Firstly, the mechanics of economic experiments that mimic real-world incentives and secondly, their capacity to elicit participants' social preferences (e.g. altruism, fairness, reciprocity) when making decisions. As such, experiments can be combined with historical, ethnographic and survey research, enabling us to study social behaviour in the field and to gain ex-ante some insight into the dynamics of community collective action. To illustrate this point, an example of a field experiment is presented here, along with some interesting findings that have been drawn empirically.

Finally, the chapter raises some additional political economy issues that deserve our attention. In particular, our discussion extends to the ramifications that emerge as we move from the microcosm of decision-making mechanics to broader concerns regarding the users and uses of heritage commons. This provides us with the space to reflect on and set certain critical parameters with which future scholarly work and public debates need to engage methodically. In turn, these reflections illustrate that the commons project is not simply a 
management model but a radical proposal that touches on and challenges deeply rooted principles and norms of our social, political and economic organisation. As is highlighted, at a time when options for socio-economic organisation seem so closely narrowed, approaching cultural heritage from a commons perspective requires us to set in motion our social imagination.

\section{State vs markets: The (pseudo)dilemma of fulfilling communal interests}

Since the $19^{\text {th }}$ century, Western European conservation and preservation practices shaped the perception of 'heritage' as monumental, aesthetic, largely material and universally significant (Kuutma 2013). The ideological roots of heritage-making and its management practices grew between Bourdieu's (1984) symbolic distinctions of elitist spaces and Anderson's (1983) fabricated communities of national imagination. Heritage policy and control of the past and its remains was granted predominantly to the state and its officials (Smith 2006; Harrison 2012). State management prescribed for the material protection of heritage resources at the expense of public engagement and socialisation, creating inequality and distancing the broader public (Smith 2009). Participatory practice, introduced to museums and heritage spaces in recent decades to tackle the latter, is still largely flawed, in many cases creating the deception of collaboration while critical power continues to rest with experts (Waterton \& Smith 2010; Lynch 2017).

Across the wider macro-economic policy landscape, recent years have seen the weakening of Keynesian politics and the destabilisation of state control over cultural heritage. However, the new policy 'shift' seems to also pay lip-service to the communal dimension of the remnants of the past. What is particularly disturbing in this case is that emerging policy trends are presented as reinstating commons qualities although in reality they serve predominantly business interests. In the current neoliberal climate, the concept of heritage commons is heavily challenged by market pressures, individualisation and the crisis of the welfare state (Callon 2007). The state is increasingly attacked for lacking the efficiency to satisfy individual needs as compared to the market. As in other sectors, recommended remedies to cure inefficiency are public sector reduction, increased marketisation and commodity consumption (e.g. by introducing user-fee services, privatisation and outsourcing schemes; Chhotray \& Stoker 2009).

Cultural heritage does not remain impervious to these changing trends. Neoliberal politics advance the idea that, similar to other types of non-marketed goods, expenditure on heritage protection and enhancement must contribute somehow to economic development (Harvey 2012). Consequently, public policy for heritage is gradually adopting a market-approach, evaluating the conservation of the past against economic impacts and measurable indicators. 
Countries such as the UK showcase this new apparatus of cultural politics by popularising the notion that the assignment of public funding to heritage must be justified in terms of its contribution to the economy (see for example, Heritage Lottery Fund 2016; Historic England 2017) and perceptual life satisfaction (see indicatively Fujiwara et al. 2014; Wheatley \& Bickerton 2017). Undeniably, reducing a collective political economy issue to a matter of individual subjective well-being is perfectly aligned with new market instrumentalism.

Parallel to this, in less affluent states, heritage-led development is presented as a solution to diversify declining or emerging economies. Related strategies position heritage as compensation for the loss of agricultural and manufacturing activities, advancing the growth of service sector industries in tourism and leisure. European policy guidelines and reports by multilateral organisations increasingly promote the conservation of the past as an 'investment' option, a source of destination 'branding' and an 'asset' that needs to be capitalised in order to contribute to material wealth (see, for example, Throsby 2012; Council of Europe 2015). This new heritage vocabulary that has taken over policy narratives illustrates quite disturbingly the intrusion of market reasoning into the sphere of heritage commons. According to this rhetoric, heritage-led development projects hold the potential to generate multiple socio-economic benefits for local communities, although these come mainly indirectly (e.g. through employment 'opportunities'). However, what the narrative conceals is that these projects establish new 'synergies' between the state and the markets. While we are left to wonder how trading 'tax-payers' money with low-paid insecure employment can contribute substantially to the public benefit and socio-economic equality, private capital directly reaps the profits of increased tourism numbers and real-estate values. Economic analyses measuring the impact of heritage sites upon real estate through hedonic pricing illustrate this point eloquently (e.g. Lazrak et al. 2014).

State practices and norms determining the relationship between cultural heritage and Greek society do not deviate much from their European counterparts. Here, heritage management has long been viewed as state responsibility and a public service (Alexopoulos \& Fouseki 2013). State authority over heritage was expressed as privileged control to official experts, exclusionary interpretation practices and political manipulation; long-standing 'traditions' that contributed to the alienation of communities from the 'official' past (Hamilakis 2007; Damaskos \& Plantzos 2008; Lekakis 2013; Fouseki \& Dragouni 2017). Furthermore, commitment to materiality was combined with a strict regulatory framework, to which compliance was hardly monitored or hindered by lengthy bureaucratic procedures and constraints on human and financial resources. In response to these shortcomings, non-expert communities developed confused, apathetic and occasionally hostile behaviour towards the ostensibly common heritage goods that had largely been isolated from their social surroundings (Stroulia \& Sutton 2009). In more recent years, Greece's sovereign debt crisis led to the imposition of draconian austerity measures that lessened its welfare 
state considerably and shrunk its public goods provisions dramatically, also compromising the heritage sector (Georganas 2013; Howery 2013). Perhaps not surprisingly, the predicament of the national economy served as a fertile ground in public dialogue for entertaining ideas favourable to the private appropriation of heritage commons (see for instance, Chasapopoulos 2012, January 09; Pournara 2013, October 14; see also Lekakis, 2017), whereas postcrisis governments showed clear intentions to promote heritage tourism more intensively (Kouri 2012).

Overall, the problem with heritage resources, in Greece and elsewhere, is that state management often fails to fulfil their common interests and effectively address their public role, operating instead as a mechanism that controls, limits and excludes (Graham 2017). Heritage resources under state authority regimes have lost their societal relevance, whereas the state-market alliances legislating for enclosures and rents threaten to further strip their communal features. As the current economic and political landscape suggests, seeing the state and markets as opposing forces is misleading (Hann \& Hart 2011). Rather, both models are imbued with failures to materialise common qualities and generate value and positive externalities that benefit society as a whole (Frischemann 2005). To our mind, any state-market synergy is condemned to fail in bringing about communal heritage benefits because private interests inherently favour specific (profit-seeking) uses of heritage, thus creating negative externalities such as the overuse and further detachment of heritage goods from their social context (Young 2011). This does not imply that heritage-related tourism and economic activities are intrinsically flawed, but rather that the economic system within which they function normally transforms them into unsustainable and destructive forces.

In this context, the management of heritage would need to move beyond the public / private logic and the choice of either the Keynesian or neoliberal canon (Hardt \& Negri 2009). The failures of public management and marketoriented development projects suggest that it is worth exploring alternative models for heritage resources management, such as those that rely on political social action on behalf of citizens in order to (re)appropriate them. Economic analysis of Common Pool Resources and Ostrom's work on self-governance provide a conceptual framework to explore the subject and most importantly, to start thinking of a socio-economic formation of collectives that would operate outside current state and market rules.

\section{The tragedy and triumph of the commons in rational economic thought}

In mainstream economic theory, the terms 'commons' or 'common-pool resources' are used to describe a particular type of institutional arrangement for governing the availability and use of a good. This arrangement suggests that 
despite their rival character (i.e. use by one agent may affect use by another), no single agent can have exclusive control over their appropriation (Ostrom et al. 1994; Benkler 2003). Rather, the commons can be used and disposed by anyone under certain formal or informal rules. Cultural heritage can be formally defined as a Common Pool Resource based on these traits. Its nonexcludability lies in the fact that it is in principle a shared good, given that exclusion from enjoying heritage is not socially and ethically acceptable. Moreover, heritage bears tangible and intangible elements of which the boundaries are often, by nature, hard to delineate. Consequently, even when access to heritage is restricted (e.g. to privately-owned historic houses) or conditional (e.g. when admission charges apply), it maintains qualities that are impossible to control, such as aesthetic pleasure or pride. In terms of rivalry, heritage is conflicting and attached to diverse use and non-use values that are often competing (Tunbridge \& Ashworth 1996; Porter \& Salazar 2005). For example, mass tourism or extreme commercialisation may generate economic benefits but lead to physical deterioration, decay and distortion of the heritage 'essence' (thus, affecting social and cultural values negatively).

Management-wise, the conceptual framework of the commons applied to the heritage realm calls for the substitution of paternalistic (state) regulation and market restrictions with recognition of commoners' rights to maintain the heritage resources of their locality (Benkler 2003). Here, economic analysis underlines the complexity of such an arrangement, suggesting that due to their non-excludable character, investment in the commons and returns of investment are disconnected. Said isolation creates externalities, as those not contributing to heritage commons cannot be excluded from enjoying the benefits of its protection and enhancement. Therefore, according to the rationality theorem, heritage resources are caught in social dilemmas, defined as situations where it is individually preferable to pursue one's personal interests instead of contributing to the commons' collective provision. This might hold especially true when social agents do not directly use heritage (as in the case of alienated communities) or when they can reap heritage-induced profits by free-riding (as in the case of tourism entrepreneurs; see Gonzalez 2014). Apart from limited incentives to invest in the maintenance and enhancement of heritage commons, the feature of rivalry, entailing the existence of certain interests pushing for heritage appropriations that clash with the uses and values of other interest groups, bears the inherent risk of excessive exploitation, overdevelopment and over-extraction of value (Briassoulis 2002).

Considering the complexities in the management of common goods, in 1968, Hardin put forward his famous proposition of the 'tragedy of the commons', advancing the idea that the collective management of a shared resource under these circumstances (i.e. no enclosures or external control) was doomed to fail. The foundation of his argument was the selfishness axiom, namely the assumption that social actors have a 'natural' tendency for profit-maximisation (Hann \& Hart 2011). Based on this line of economic thought, dilemma situations are 
critical because the temptation to refuse cooperation can lead to less optimal provisions of communal benefits and eventually impair heritage goods, leaving everyone worse-off. To resolve such dilemmas, Hardin (1968) recommended either a top-down management or the privatisation of heritage goods (the failures of which we discussed earlier in this chapter).

Contrary to Hardin, Elinor Ostrom (1990) took the opposite stance towards the subject. In her seminal work, Governing the commons, she moved beyond both centralised government and private sector management to propose collective choice arrangements as a means of avoiding 'tragedy' situations. She suggested that communities can solve social dilemmas through a process of self-governance, which was subject to institutional arrangements (i.e. locally set rules). Based on Ostrom's (1990) metaphor, heritage resources can be positioned as the 'common-pools' of a locality, community members as 'providers' of these pools and the broader public as their 'appropriators' (e.g. through joint use and visitation). In a decentralised governance arrangement, invested provisions will benefit all appropriators but community agents will be granted the authority to collaboratively maintain heritage common resources.

The latter generates interest in the processes and dynamics of participation in decision-making, with regards to how heritage goods will be managed by commoners. Admittedly, a core problem of collective action relates to the interplay between individual action and outcomes dependent on others (Berge \& van Laerhoven 2011). Nonetheless, presuming that individuals will de facto engage in the anti-social pursuit of profit is an oversimplification of human reasoning. In fact, both economic history and social anthropology suggest otherwise, rejecting the idea that humans strive to maximise utility and instead emphasising the existence of psychological drivers as complex structures shaped by the interplay between personal gain, consideration for others and social acceptance (Eriksen 2004). Thus, research into heritage commons needs to explore the internal mechanics of a collective process, as these would ultimately determine the viability of the resources in question.

While Ostrom's work exhibited cases where a commons regime could be successful at a micro level (mainly on natural resources management), we have little evidence at hand regarding its feasibility in a heritage context. Undeniably, one of our main challenges as scholars with an interest in the subject is the fact that both self-governance and the autonomy to make decisions are extremely uncommon phenomena. In some respects, the heritage commons call for a socio-political system that resembles Arnstein's (1969) citizen power levels, at a time when the prevailing paradigm for heritage management is top-down state control (Cleere, 2012). Thus, inevitably, we face the problem of limited, naturally occurring data on collective behaviour for heritage commons in order to study the cooperative capacity of social actors. This not only weakens the convincing power of theoretical arguments in favour of the commons but also hinders empirical enquiry on the subject as a means to inform the implementation of self-governance models in the real world. Since traditional observational 
approaches are not easily applicable to heritage commons studies, we propose here the use of economic experiments as alternative methodological tools that open up a novel avenue of research into the topic. Considering the growing experimental work on critical issues related to people's preferences, behaviour and decision-making, it is plausible to argue that experimental protocols can be adapted to respond to questions related to heritage self-governance and community cooperation in places where top-down management culture still prevails.

More specifically, economic experiments can capture participants' behaviour in a real setting by implementing actual pay-off structures associated with their choices (Exadaktylos et al. 2013). As such, they have been used to explore policy issues through the study of social preferences, where human subjects are asked to make economic decisions with real stakes. Experimental economics have consistently exposed the flaws of normative assumptions rooted in the selfishness axiom by demonstrating that human subjects do not innately engage in an anti-social pursuit of individual gain. Rather, systematic experimentation through economically incentivised protocols have shown that pro-social behaviour is associated with some form of conditional cooperation (Brandts \& Fatas 2012). Exploring such conditions, therefore, deserves our scientific attention. In addition, experimental evidence has linked subjects' choices with the economic, social and cultural environments in which they operate. ${ }^{8}$ These observations are highly relevant to a commons-based socio-economic organisation and can inform research in communities that currently have limited experience of collective action.

Similar to other policy contexts, experimental tools could be employed to elicit community commitment to heritage commons at the cost of personal rewards and generate observational data on their revealed preferences. In essence, this means that there is potential for studying community-based management of heritage ex-ante by devising experimental procedures that imitate circumstances of self-governance with the view to testing relevant hypotheses empirically and by design. Such hypotheses may relate to social interaction and cooperation, where heritage protection depends upon the collective decisions of participants. A model of self-governance for heritage commons presupposes direct responsibility on behalf of community members for both policy formulation and outcomes (Ansell \& Gash 2008). This would suggest that, similar to Ostrom's (1990) framework, where self-governance is based upon the voluntary cooperation of community members, the maintenance and enhancement of heritage commons will be dependent on collective decisions to contribute.

Therefore, we argue that experimental research in the field of heritage can complement qualitative (e.g. ethnographic) and quantitative approaches (e.g. surveys) by increasing our understanding of cooperation dynamics in action.

${ }^{8}$ In this regard, the cross-cultural field experiments of Henrich et al. (2004) were particularly revealing in demonstrating the influence of socioeconomic organisation systems upon people's responses to social dilemmas. 
Given the similar arrangements needed for Common Pool Resources and public goods (Ostrom et al. 1994), researchers can create variations of publicgood experiments in order to investigate behaviour when individual interests clash with social returns (Van Winden et al. 2008). In order to illustrate how experimental protocols can be employed to explore heritage commons questions, the next section will describe a hands-on application and briefly discuss its empirical results.

\section{Studying the dynamics of collectives: A field experiment}

During the Autumn of 2015, we ran a series of field experimental sessions with the community of Kastoria in Greece with the view to testing collaborative decision-making for heritage in a locality with no recent experience of selfgovernance. Kastoria was an interesting case study that exemplified a remote community and heritage at risk. This was highlighted by the 2014 Europa Nostra '7 most endangered' list, ${ }^{9}$ which included the city's historic districts and by the dramatic socio-economic circumstances that heavily affected the area at the time (i.e. national debt crisis, decline in local manufacturing, extreme unemployment, increasing migrant population).

The experiment drew all of its subjects from the local community, encompassing residents, heritage professionals and government representatives. The key aim was to explore the collective processes of decision-making for heritage and the effect of different local group compositions upon cooperation. With this in mind, we organised participants into small groups and assigned them three different treatments. These imitated (a) conventional top-down management by state experts and officials, (b) bottom-up citizen leadership and (c) mixed arrangements of both officials and citizens that reflected a more pluralist form of heritage governance (Figure 1).

Inspired by public good protocols, the experiment featured two realistic management scenarios for heritage development projects, specifically designed
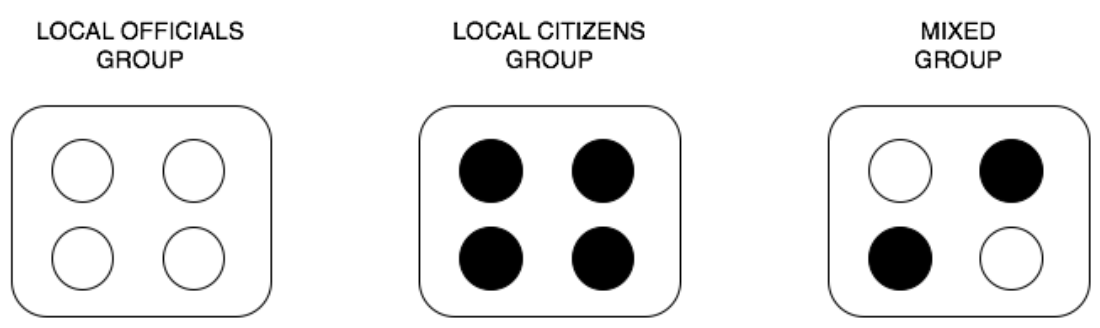

Figure 1: Experimental treatments (Source: author, 2019).

\footnotetext{
${ }^{9}$ Available at: http://7mostendangered.eu/sites/neighbourhoods-of-dolcho -and-apozari-kastoria-greece/. Last accessed 20 November 2019.
} 


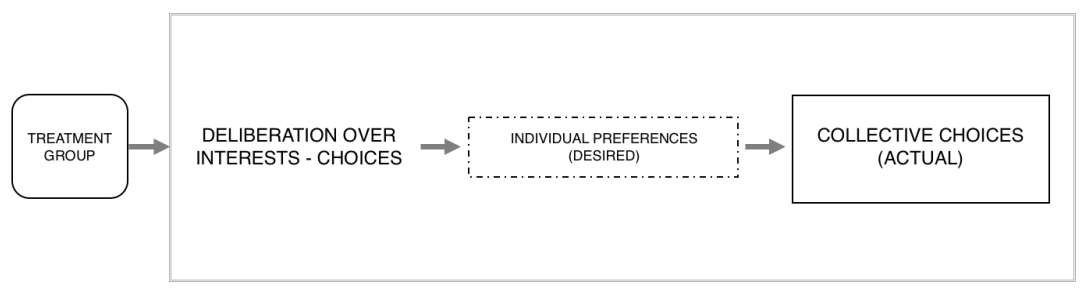

Figure 2: Process followed by each group and observed during experimental sessions (Source: author, 2019).

to fit with the local context. The actual implementation of these scenarios relied upon participants' choices and the resources they would be willing to contribute to the proposed projects. At each round, a voluntary contributions mechanism assigned the groups with an endowment and a simple task to allocate resources between a heritage account and a private account. Contributions to the heritage account would be used to fund the heritage project in question whereas contributions to the private account would be shared amongst group members for any other use. Each group was requested to reach a joint decision on how to use their endowment and note their decisions in privacy (to avoid any inter-group influences). Intra-group deliberation was recorded to extract data on individuals' (desired) choices and conflict (Figure 2). Responses to a personal questionnaire were also collected at the beginning of the sessions in order to observe how participants' background and beliefs shaped individual and group preferences during decision-making. Overall, the generated data allowed us to compare behaviour across different collective settings, the causes and impact of conflict upon collaboration and negotiations between an individual's own preferences and communal choices.

Based on the widely accepted assumptions about the tragedy of the commons, we would expect that in this collective-action situation, community members would act as rational egoists, generating a deficient equilibrium of zero or very low contributions to heritage (Ostrom 2005). However, as revealed by the experimental results, the local community of Kastoria presented significantly high social preferences and generosity towards heritage, despite its serious socio-economic problems, its lack of previous political traditions of collective action and its relative alienation from what was considered 'official' heritage. ${ }^{10}$ Composition-wise, groups aligning with top-down management and pluralist groups that included officials and citizens as equal partners made equally pro-social choices. Interestingly, autonomous citizen groups were less co-operative in the first round, but equally co-operative in the second round.

${ }^{10}$ Based on survey-based empirical research that preceded the experiment (see Dragouni \& Fouseki 2018). 
This heterogeneity was possibly related to the different uses of heritage proposed by each scenario. ${ }^{11}$

In terms of deliberation dynamics, citizen and mixed groups were more susceptible to conflict situations, but interestingly their disagreement was positively related with their contributions to the heritage account (the opposite held true for the groups of officials). Furthermore, their collective decisions were consistently higher than the average individual preferences of group members. These suggest that conflict played a positive role during deliberation as it increased cooperation for heritage, showing higher resistance to egotistical interests compared to counterfactuals. In fact, the content of the group discussions revealed that negotiation dynamics (e.g. accommodating vs. contending behaviour) were instrumental in determining whether conflict would act favourably or against heritage commons. This has important implications for heritage self-management, highlighting that dealing with internal conflict can be a constructive democratic process rather than a destructive force. Conflict resolution reflects participants' freedom to challenge the direction of a common project (Kallis \& March 2015) and in our case, it mobilised contributions to heritage commons. This mobilisation was dependent on certain negotiation merits and in particular, tolerance to participants' right to hold a different opinion and continuous deliberation on the available options.

In terms of drivers to cooperation, we found that trust (either in citizens or experts, depending on the sub-sample) played a significant role in determining social preferences at an individual level. Likewise, doubts within groups over the credibility of central authorities and external private players to manage heritage impacted positively on cooperation. In contrast, groups exhibiting high discrepancies with regards to the credibility of local actors, such as local heritage experts and community associations, tended to invest less in heritage commons. These findings are important because they underline the decisive role of trust at local level as a condition of cooperation and successful management of heritage by communities themselves. Qualitative data extracted from deliberation lent support to this argument, as distrust was one of the most frequent causes of dispute during decision-making. The role of trust in our experimental setting contradicts conventional theories of collective action problems, which emphasise the importance of material incentives (Kahan 2005). Rather, our results subscribe to a shift away from pure incentives towards the cultivation of trust as a key driver to cooperation. ${ }^{12}$

Although it is acknowledged that this empirical study would benefit greatly from future replication and comparison, it is maintained that it can introduce

${ }^{11}$ According to deliberation content analysis, the first scenario was seen as benefitting mostly tourism stakeholders whereas the second was mainly educational in nature.

12 For a full description of the experimental design and results please refer to Dragouni et al. 2018. 
a new and exciting line of research into the subject. Based on our experience of using an experimental method to observe community behaviour at the field, it is argued that diversifying our research tools and being scientifically 'creative' can be particularly rewarding not only in terms of research outputs but also as a process in itself. As discussed by Cardenas and Carpenter (2005), field experiments create benefits for both experimenters and participants, as a process of reflection on communal issues and problems. Indeed, as researchers we felt that the experimental sessions provided a platform for local stakeholders to meet and share their thoughts on heritage, while the whole process eventually led to the implementation of one of the project scenarios by the local heritage office, producing additional benefits to the community under study. It is hoped that our experience and results will provide an eloquent example of the methodological directions available at hand from other disciplines - in this case, experimental economics - and their capacity to meaningfully inform scientific research and public debate regarding heritage commons.

\section{Moving from micro to macro: reflections on broader issues of political economy}

Exploring the mechanics of decision-making processes and management arrangements at a micro level would be valuable for informing questions regarding heritage commons. Nonetheless, we maintain that the discussion on heritage commons also needs to engage in broader issues of political economy, as these are critical for understanding our current position, defending the concept, and visualising future steps towards self-governance. In particular, we argue that there are important parameters that deserve further consideration and these relate primarily to (i) the users and (ii) the uses of heritage commons. In turn, these reflections raise broader questions of political economy that touch upon the self-governance of heritage shared resources. By raising these questions, our intention is not to respond but rather to start painting the wider picture of the subject as an economic and political problem.

As previously implied, the ideal of the heritage commons is to form the groundwork for non-exclusive politics of collectivism. By encouraging processes of collective working, the commons arrangements are expected to tackle community alienation and promote equality (i.e. rectify the failures of current management approaches). Heritage studies have long been advocating for the 'opening up' of heritage management systems from top-down to more community-inclusive processes. However, this proposition, rooted in ideas of post-colonial justice, cannot be easily applied to the fragmented and shifting communities located in Western European territories. Therefore, a critical question arises regarding which community or communities are entitled to manage heritage commons. As Waterton and Smith (2010) stress, the concept of community seeks to draw arbitrary divisions across society to construct supposedly homogeneous sub-collectives. 
Considering the multiplicity of interest groups with stakes in heritage resources it becomes clear that a key parameter that deserves consideration is whether heritage commons and their management will be open to anyone or only to specific groups. Ostrom's examples describe limited-access commons collectively 'owned' by a village or an association. Having clearly defined communities can become particularly problematic in the heritage field because heritage communities are not static or spatially defined entities. In addition, even if communities are somehow defined (e.g. based on physical proximity to the shared resource), they may still have hidden hierarchical divisions. Internal hierarchies are of particular concern as they can end up changing power relations amongst stakeholders without disposing their repressive character locally (Herzfeld 2010). Yet, truly democratic systems, such as those envisaged through commons ideology, need to provide space for the expression of minorities and appease socio-economic inequalities amongst its members. A decentralised heritage governance arrangement that maintains its inner antagonisms can merely shift but cannot eliminate power imbalances. Failure to do so will hamper the capacity of communities to address commons problems successfully (Bowles \& Gintis 2005).

Thus, a true and meaningful change would call for a horizontal management model in order to effectively promote equality. This marks a break from the 'top-down' and 'bottom-up' heritage management schemata that exist in current theory and practice. Furthermore, it suggests that behind questions on the commons lie acute social and political interests. While our vision is that the democratic advantages of decentralised horizontal processes will lead to heritage and citizenship enhancement to multiply societal benefits, our present reality is imbued with top-down rules and political norms, essentially leaving us with minimum experience of said social organisation structure. Again, Ostrom's work provides limited solutions to these concerns as it proposes the function of the commons as nested enterprises, working within wider systems, requiring again some sort of hierarchical organisational forms (Harvey 2012). For other researchers, such as Frischmann (2005), the degree of openness depends ultimately on economic considerations, the ways in which the resource is used to generate value, the community setting and its demands.

This leads us to our second key consideration of whether heritage commons management should discriminate certain uses of the heritage resource. If the heritage commons are constructed to address the failures of current management regimes (e.g. alienation, over-extraction of value and unfair distribution of benefits), the question that follows is what objectives and goals would their 'rules-in-use' serve in order to do so (Maddison et al. 2010). According to Harvey (2012), commons should be treated as non-commodified resources, lying outside of the market exchange logic. Yet heritage goods, even if they are not commodities themselves, can be traded to extract economic rents (e.g. through tourism and leisure activities). Still, their viability would require commitments 
that are antithetical to market competition and bear costs to the local economy since, despite the rhetoric, growth and sustainability are contradictory in nature. At the same time, given that heritage resources exert and receive pressures from competing economic interests, they may be seen as 'liabilities' in the eyes of alienated communities (Chirikure et al. 2010). It is therefore important to consider and explore the broader contextual economic factors that frame the present reality, should we wish to engage meaningfully in a discussion of heritage self-governance.

Small-scale economies functioning along the commons lines provide some valuable insight into effective solutions based on solidarity. However, jumping from clearly defined social and economic boundaries to larger-scale problems of socio-economic organisation increases complications dramatically (Harvey 2012). It is on this point that a major question needs to be posed; if heritage commons operate locally but still in dependency to broader politico-economic forces, can they really manage to refrain from serving markets and industries? Contradictions between the ideals of commons self-governance and the broader economic fixes could easily threaten their long-term survival. At a macro level, market capitalism has been crystallised as the global economic paradigm. This paradigm promotes the delusion of unlimited choice at the same time that practically favours scarcity through enclosures, inequalities and the 'fetishisation' of economic growth (Harvey 2007; Kallis \& March 2015). The quest for growth should not be underemphasised as it is an imperative that is maintained by the relevant institutions that make up the 'rules of the game' macro-economically, as seen in 'grow-or-die' competition (Kallis 2011). Since the ideal of the commons marks a sharp contrast to such mechanics and rules, the question that inevitably plagues us is whether heritage commons can be implemented effectively within the context of market economies and their property rights, their financial and political institutions and their lack of effective income redistribution mechanisms.

Heritage commons is therefore not merely a management concept - it is a radical political project. Our argument is that public debate and scholarly work in the heritage commons apart from negotiating with internal issues and complexities needs to move a step further and challenge directly the current economic system. This is not an option but rather a necessity as the economic system is a central function of our social organisation (Polanyi 1957). Therefore, it is possible that the theoretical and practical development of heritage commons as a political project needs to be linked to the vision of a shift from the prevalent economic paradigm. Needless to say, advocating for and planning such a shift would be anything but an easy task. This is because the foundations of our present economic and social organization, such as ownership, inheritance rights and central state administration, are persistent long-lived concepts that have determined not only our institutional structures and political constitutions but also our intuitive understanding of social reality (Badiou 2017). Thus, we hold that the first step would be for our imagination to escape the 
diachronic dictates of growth and material accumulation, sustained diachronically by hierarchical ideologies that defined the social evolution of Western societies (Latouche 2009). In essence, the idea of the commons is a quest for an alternative polity. Thinking about such alternative is not merely a methodological problem but an ontological one (Curtis 2013). It is time to dare to think of a different world, if we wish to provide the heritage commons project with the opportunity to be realised or at least, pursued.

\section{Conclusion}

This chapter attempted to pose and reflect on some theoretical, methodological and broader macro-economic questions related to heritage commons. It provided an analysis of the economic thinking that dictates the present reality and policy along with the theoretical economic concepts that lie behind it. As analysed, neoclassical economics predicts that communities using heritage collectively will face a tragic situation in which individual rationality will lead to destructive outcomes. The neoclassical paradigm and its obsession with the utility calculations of Homo Economicus epistemologically undermined the sociological and psychological dimensions of economic exchanges. In contrast, Ostrom's theory, although remaining consistent to the rational choice hypothesis, departed from the mainstream economic thinking of her time. In her work, self-governance was set as a central characteristic of commons' success, granting community the power to devise its own rules of participation and use. Her research demonstrated the impact of formal and informal institutions on human behaviour and showed that collective forms of ownership can be successful at a micro level.

Inspired by Ostrom's principles, this chapter proposed the use of experimental approaches as a means to address the implications that arise from the scarcity of naturally-occurring data in modern-state polities. Experimental economics, although rooted in rational economic thinking, allow us to observe not merely rational elements but also behavioural aspects that often contradict the utility axiom. As such, they can serve to empirically study critical features of collective decision-making for heritage resources management under a commons arrangement and thus inform the transferring of the concept to the real world. Our field experiment in Kastoria provided an actual example of how experimental protocols can be adapted to elicit community attitudes, processes and responses to communal heritage problems.

Undeniably, a mere understanding of institutions and rules at micro-environments is not sufficient in itself. As we move from controlled environments to the macro levels of our social ecosystem, critical questions of political economy emerge. Who would be involved in the commons management, how power relations would work, what aims and uses of the heritage resources would be 
acceptable and favourable are amongst the many critical considerations that we need to explore further. The commons project marks a sharp contrast to the rules and workings of central-state administration and market economy and it is antithetical to political norms and power relations that diachronically shaped our social evolution. Since the commons cannot operate autonomously from these forces, it is imperative that relevant research and future debate does not remain confined to internal mechanics but also looks at the broader politicoeconomic picture to identify the conditions that call for change in order to make the concept feasible.

Overall, this chapter attempted to provide a first touch rather than an indepth analysis of some fundamental theoretical, methodological and macroeconomic issues that permeate the realm of heritage commons. Our position is that the concept of self-governance is largely an unknown territory to Western political traditions and current socio-economic forms of organisation. Nevertheless, considering the management failures of state and market agents, the concept and questions around heritage commons are particularly worthy of negotiation. Addressing them effectively will be anything but easy. In our capacity as scientists, we need to remain open-minded and embark on mixed methodological approaches that along with traditional tools, such as ethnography and historical research, will also draw on 'unorthodox' research methods inspired by other disciplines. In our capacity as social actors and citizens, we need to employ our social imagination and think of a radically different world. Confronted with the limitation of space, this chapter attempted to stimulate its readers to set their imagination in motion.

\section{Bibliography}

Alexopoulos, G. \& Fouseki, K. (2013). Introduction: Managing archaeological sites in Greece. Conservation and Management of Ar chaeological Sites, 15(1), 1-12.

Anderson, B. (1991). Imagined communities: Reflections on the origin and spread of nationalism. London, United Kingdom: Verso.

Ansell, C. \& Gash, A. (2008). Collaborative governance in theory and practice. Journal of public administration research and theory, 18(4), 543-571. DOI: https://doi.org/10.1093/jopart/mum032.

Arnstein, S. R. (1969). A ladder of citizen participation. Journal of the American Institute of Planners, 35(4), 216-224. DOI: https://doi.org /10.1080/01944366908977225.

Badiou, A. (2017). On the Russian October revolution of 1917. Crisis and Critique, 4(2), 13-23.

Benkler, Y. (2003). The political economy of commons: Upgrade. The European Journal of the Informatics Professional, 4(3), 6-9. 
Berge, E. \& van Laerhoven, F. (2011). Governing the commons for two decades: A complex story. International Journal of the Commons, 5(2), 160-187. DOI: http://doi.org/10.18352/ijc.325.

Bourdieu, P. (1984). Distinction: A social critique of the judgement of taste. London, United Kingdom: Routledge.

Bowles, S. \& Gintis, H. (2005). Social capital, moral sentiments, and community governance. In H. Gintis, S. Bowles, R. Boyd \& E. Fehr (Eds.), Moral sentiments and material interests: The foundations of cooperation in economic life (pp. 379-398). Cambridge, MA: The MIT Press.

Brandts, J. \& Fatas, E. (2012). The puzzle of social preferences. Revista Internacional de Sociologia, 70(Extra_1), 113-126. DOI: https://doi.org /10.3989/ris.2011.09.03.

Briassoulis, H. (2002). Sustainable tourism and the question of the commons. Annals of tourism research, 29(4), 1065-1085. DOI: https://doi.org/10.1016 /S0160-7383(02)00021-X.

Callon, M. (2007). An essay on the growing contribution of economic markets to the proliferation of the social. Theory, Culture \& Society, 24(7-8), 139-163. DOI: https://doi.org/10.1177/0263276407084701.

Cardenas, J. C. \& Carpenter J. P. (2005). Three themes on field experiments and economic development. In J. P. Carpenter, G. W. Harrison, \& J. A. List (Eds.), Field experiments in economics. Research in Experimental Economics, Vol. 10 (pp. 71-123). Oxford, United Kingdom: Elservier.

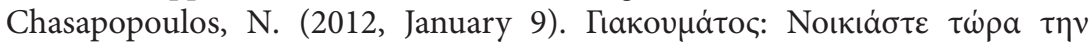

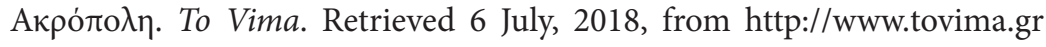
/politics/article/?aid=437898.

Chhotray, V. \& Stoker, G. (2009). Governance theory and practice: A cross -disciplinary approach. Basingstoke, United Kingdom: Palgrave Macmillan.

Chirikure, S., Manyanga, M., Ndoro, W. \& Pwiti, G. (2010). Unfulfilled promises?: Heritage management and community participation at some of Africa's cultural heritage sites. International Journal of Heritage Studies, 16(1-2), 30-44.

Cleere, H. (2012). Introduction: the rationale of archaeological heritage management. In H. Cleere (Ed.), Archaeological heritage management in the modern world (pp. 1-22). London, United Kingdom: Routledge.

Council of Europe. (2015). The wider benefits of investment in cultural heritage. Retrieved July 6, 2018, from https://book.coe.int/usd/en/cultural -heritage/6454-the-wider-benefits-of-investment-in-cultural-heritage.html.

Curtis, N. (2013). Idiotism: Capitalism and the privatisation of life. London, United Kingdom: Pluto Press.

De Angelis, M. (2003). Reflections on alternatives, commons and communities. The Commoner, 6, 1-14.

Dragouni, M. \& Fouseki, K. (2018). Drivers of community participation in heritage tourism planning: an empirical investigation. Journal of Heritage Tourism, 13(3), 237-256. DOI: https://doi.org/10.1080/1743873X.2017 .1310214 . 
Dragouni, M., Fouseki, K. \& Georgantzis, N. (2018). Community participation in heritage tourism planning: is it too much to ask? Journal of Sustainable Tourism, 26(5), 759-781. DOI: https://doi.org/10.1080/09669582.2017 .1404606 .

Eriksen, T. H. (2004). What is anthropology? London, United Kingdom: Pluto Press.

Exadaktylos, F., Espín, A. M. \& Brañas-Garza, P. (2013). Experimental subjects are not different. Scientific Reports, 3(1213), 1-6.

Fouseki, K. \& Dragouni, M. (2017). Heritage spectacles: the case of Amphipolis excavations during the Greek economic crisis. International Journal of Heritage Studies, 23(8), 742-758. DOI: https://doi.org/10.1080/13527258 .2017.1321573.

Frischmann, B. M. (2005). An economic theory of infrastructure and commons management. Minnesota Law Review, 89, 917-1030.

Fujiwara, D., Cornwall, T. \& Dolan, P. (2014). Heritage and wellbeing. London, United Kingdom: English Heritage.

Georganas, I. (2013). The effects of the economic crisis on Greek heritage: A view from the private cultural sector. Journal of Eastern Mediterranean Archaeology \& Heritage Studies, 1(3), 242-245. DOI: https://doi.org /10.5325/jeasmedarcherstu.1.3.0242.

Gonzalez, P. A. (2014). From a given to a construct: Heritage as a commons. Cultural Studies, 28(3), 359-390. DOI: https://doi.org/10.1080/09502386 .2013.789067.

Graham, H. (2017), Horizontality: Tactical politics for participation and museums. In B. Onciul, M. L. Stefano \& S. Hawke (Eds.), Engaging heritage: Engaging communities (pp. 73-87). Woodbridge, United Kingdom: The Boydell Press.

Hamilakis, Y. (2007). The nation and its ruins: Antiquity, archaeology, and national imagination in Greece. Oxford, United Kingdom: Oxford University Press.

Hann, C. \& Hart K. (2011). Economic anthropology. Cambridge, United Kingdom: Polity Press.

Hardin, G. (1968). The Tragedy of the commons. Science, 162(3859), 1243-1248.

Hardt, M. \& Negri, A. (2009). Commonwealth. Cambridge, MA: Belknap Press.

Harrison, R. (2012). Heritage: Critical Approaches. London, United Kingdom: Routledge.

Harvey, D. (2007). The limits to capital. London, United Kingdom: Verso.

Harvey, D. (2012). Rebel cities: From the right to the city to the urban revolution. London, United Kingdom: Verso.

Henrich, J., Boyd, R., Bowels, S., Camerer, C., Fehr, E. \& Gintis, H. (Eds.). (2004). Foundations of human sociality: Economic experiments and ethnographic evidence from fifteen small-scale societies. Oxford, United Kingdom: Oxford University Press. 
Heritage Lottery Fund. (2016). Values and benefits of heritage: A research review. Retrieved July 6, 2018, from https://visionforsidmouth.org/wp-content /uploads/2019/05/values_and_benefits_of_heritage_2015.pdf.

Herzfeld, M. (2010). Engagement, gentrification, and the neoliberal hijacking of history. Current Anthropology, 51(S2), S259-S267. DOI: https://doi .org/10.1086/653420.

Historic England. (2017). Heritage counts 2017: Heritage and the economy. Retrieved July 6, 2018, from https://historicengland.org.uk/content/heritage -counts/pub/2017/heritage-and-the-economy-2017-pdf/.

Howery, C. (2013). The effects of the economic crisis on archaeology in Greece. Journal of Eastern Mediterranean Archaeology \& Heritage Studies, 1(3), 249-250. DOI: https://doi.org/10.5325/jeasmedarcherstu.1.3.0249.

Kahan, D. M. (2005). The logic of reciprocity: Trust, collective action and law. In H. Gintis, S. Bowles, R. Boyd \& E. Fehr (Eds.), Moral sentiments and material interests: The foundations of cooperation in economic life (pp. 339-378). Cambridge, MA: The MIT Press.

Kallis, G. (2011). In defence of degrowth. Ecological Economics, 70(5), 873-880. DOI: https://doi.org/10.1016/j.ecolecon.2010.12.007.

Kallis, G. \& March, H. (2015). Imaginaries of hope: The utopianism of degrowth. Annals of the Association of American Geographers, 105(2), 360-368. DOI: https://doi.org/10.1080/00045608.2014.973803.

Kouri, M. (2012). Merging culture and tourism in Greece: An unholy alliance or an opportunity to update the country's cultural policy? The Journal of Arts Management, Law, and Society, 42(2), 63-78. DOI: https://doi.org/10 $.1080 / 10632921.2012 .685688$.

Kuutma, K. (2013). Between arbitration and engineering: Concepts and contingencies in the shaping of heritage regimes. In R. F., Bendix, A. Eggert \& A. Peselmann (Eds.), Heritage regimes and the state (pp. 21-36). Göttingen, Germany: Universitätsverlag Göttingen.

Latouche, S. (2009). Farewell to growth. Cambridge, United Kingdom: Polity Press.

Lazrak, F., Nijkamp, P., Rietveld, P. \& Rouwendal, J. (2014). The market value of cultural heritage in urban areas: An application of spatial hedonic pricing. Journal of Geographical Systems, 16, 89-114.

Lekakis, S. (2013). Distancing and rapproching: Local communities and monuments in the Aegean Sea: A case study from the island of Naxos. Conservation and Management of Archaeological Sites, 15 (1), 76-93. DOI: https://doi.org /10.1179/1350503313Z.00000000048.

Lekakis, S. (2017, May 4-7). Cultural heritage in the realm of the commons. Paper presented at the $1^{\text {st }}$ National Conference on Commons and Social \& Solidarity Economy in Greece, Thessaloniki. Retrieved July 6, 2018, from https://www.academia.edu/32902575/Cultural_heritage_in_the_realm _of_the_commons. 
Lynch, B. (2017). The gate in the wall: Beyond happiness-making museums. In B. Onciul, M. L. Stefano \& S. Hawke (Eds.), Engaging heritage, engaging communities (pp. 11-29). Woodbridge, United Kingdom: The Boydell Press.

Ostrom, E. (1990). Governing the commons. Cambridge, United Kingdom: Cambridge University Press.

Ostrom, E. (2005). Policies that crowd out reciprocity and collective action. In H. Gintis, S. Bowles, R. Boyd \& E. Fehr (Eds.), Moral sentiments and material interests: The foundations of cooperation in economic life (pp. 253-275). Cambridge, MA: The MIT Press.

Ostrom, E., Gardner, R. \& Walker, J. (1994). Rules, games, and common-pool resources. Ann Arbor, MI: University of Michigan Press.

Polanyi, K. (1957). The great transformation: The political and economic origins of our time. Boston, MA: Beacon Press.

Porter, B. W. \& Salazar, N. B. (2005). Heritage tourism, conflict, and the public interest: An introduction. International Journal of Heritage Studies, 11(5), 361-370. DOI: https://doi.org/ 10.1080/13527250500337397.

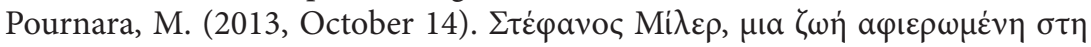

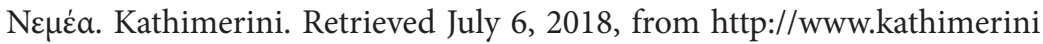
.gr/71445/article/proswpa/synentey3eis/stefanos-miler-mia-zwh-afierw menh-sth-nemea.

Smith, L. (2006). Uses of heritage. London, United Kingdom: Routledge.

Stroulia, A. \& Sutton, S. B. (2009). Archaeological sites and local places: connecting the dots. Public Archaeology, 8(2-3), 124-140. DOI: https://doi .org/10.1179/175355309X457187.

Throsby, D. (2012). Investment in urban heritage. Economic impacts of cultural heritage projects in FYR Macedonia and Georgia. Retrieved July 6, 2018, from http://siteresources.worldbank.org/INTURBANDEVE LOPMENT/Resources/336387-1169585750379/UDS16_Investment+in + Urban+Heritage.pdf.

Van Winden, F., Van Dijk, F. \& Sonnemans, J. (2008). Intrinsic Motivation in a Public Good Environment. In C. R. Plott \& V. L. Smith (Eds.), Handbook of Experimental Economics: Results, vol.1 (pp. 836-845). Amsterdam, The Netherlands: Elsevier.

Waterton, E. \& Smith, L. (2010). The recognition and misrecognition of community heritage. International Journal of Heritage Studies, 16(1-2), 4-15. DOI: https://doi.org/10.1080/13527250903441671.

Wheatley, D. \& Bickerton, C. (2017). Subjective well-being and engagement in arts, culture and sport. Journal of Cultural Economics, 41, 23-45.

Young, O. (2011). Land use, environmental change, and sustainable development: the role of institutional diagnostics. International Journal of the Commons, 5(1), 66-85. 
